\title{
Revisão Sistemática da Literatura sobre Tecnologias digitais de informação e comunicação de tradução do par linguístico Português Libras
}

\author{
Systematic Review of the Literature on Digital Information and Communication \\ Technologies for Translation of the Linguistic Pair Portuguese Libras
}

\author{
ARAÚJO, Aline Cássia S. Titulação/Tradutora Intérprete de Libras \\ Instituto Federal de Educação, Ciências e Tecnologia do Sertão Pernambucano - Campus Salgueiro. Endereço da \\ instituição - Salgueiro - Pernambuco - Brasil. CEP: 56000-000 E-mail: aline.araujo@ifsertao-pe.edu.br
}

OLIVEIRA, Francisco Kelsen. Doutor em Ciência da Computação

Instituto Federal de Educação Ciência e Tecnologia do Sertão Pernambucano-IFŠertãoPE - Campus Salgueiro. BR 232, Km 08 - Salgueiro - Pernambuco - Brasil. CEP:56.000-000 / Telefone: (85) 98817-8151 / E-

mail:francisco.oliveira@ifsertao-pe.edu.br

\section{RESUMO}

0 tradutor intérprete de Libras tem um papel fundamental para garantir acessibilidade linguística aos surdos no ambiente escolar. Nesse sentido, objetivamos através dessa Revisão Sistemática da Literatura (RSL) identificar e classificar os softwares de tradução português-Libras que poderão auxiliar os surdos na aprendizagem de conteúdo que são ministrados em sala de aula. A análise foi realizada apenas em artigos e trabalhos completos publicados em anais de eventos disponíveis na plataforma de busca google acadêmico. Os resultados encontrados nesta pesquisa se deram a partir das perguntas da pesquisa e suas motivações. Concluindo assim, que os softwares são mais utilizados com foco no ensino do que de comunicação.

Palavras-chave: Tecnologia assistiva; software tradutor português-Libras; tradutor intérprete de Libras.

\begin{abstract}
Libras' interpreter translator plays a key role in ensuring language accessibility to the deaf in the school environment. In this sense, we aim through this Systematic Literature Review (RSL) to identify and classify Portuguese-Libras translation software that can assist deaf people in learning content that are taught in the classroom. The analysis was performed only in articles and complete papers published in the field of events available on the google academic search platform. The results found in this research were based on the questions of the research and their motivations. In conclusion, software is used more with a focus on teaching than communication.
\end{abstract}

keywords: Assistive technology; translator software Portuguese-Libras; Libras' interpreter translator. 


\section{Introdução}

A surdez pode ser definida como sendo a perda em maior ou menor grau da percepção normal dos sons. Para começar a causar repercussões na aquisição da linguagem e da fala, o déficit auditivo precisa se dar entre quarenta e setenta decibéis (pessoa com surdez moderada). São inúmeras as causas de surdez, podendo ocorrer através de transmissão genética (ex.: na síndrome de Alport); patologias congênitas (ex.: síndrome da rubéola congênita); como efeito colateral de medicações (ex.: uso de quinidina); exposição a ruídos de forma prolongada, ou mesmo como um processo natural do envelhecimento.

Segundo GANDRA (2019), no Brasil existem 10,7 milhões de pessoas com algum grau de deficiência auditiva, sendo $21,49 \%$ desse total com deficiência severa. Também se mostrou que a surdez é mais comum entre os homens e predomina na faixa etária dos sessenta ou mais anos. Ainda segundo essa publicação, seis em cada dez brasileiros com deficiência auditiva têm dificuldade em realizar atividades habituais. Já com relação à escolaridade, viu-se que apenas 7\% dos indivíduos com surdez possuem o ensino superior completo, $15 \%$ frequentaram a escola até o ensino médio, 46\%, até o ensino fundamental e $32 \%$ não têm nenhum grau de instrução.

A RESOLUÇÃO CNE/CEB Nº 2, DE 11 DE SETEMBRO DE 2001, no seu artigo segundo, define os sistemas de ensino devem matricular todos os alunos, cabendo às escolas organizar-se para o atendimento aos educandos com necessidades educacionais especiais, assegurando as condições necessárias para uma educação de qualidade para todos (RESOLUÇÃO CNE/CEB, 2001).

Baseando-se nos preceitos da acessibilidade e tomando como base a supracitada resolução, torna-se fundamental a figura do tradutor intérprete de Libras no ambiente escolar. Este profissional tem por finalidade garantir a acessibilidade linguística, intermediando a comunicação entre surdos e ouvintes, ou seja, professores e alunos, não só na sala de aula, mas em todos os ambientes da instituição de ensino, bem como em todas as atividades de ensino, pesquisa e extensão. Ele pode atuar em seminários, palestras e conferências. As estratégias de tradução e interpretação que são utilizadas pelos intérpretes de libras são ferramentas fundamentais para uma boa compreensão do conteúdo traduzido, garantindo assim ao aluno surdo uma maior e melhor interação não só com seus 
professores, mas também com seus colegas.

Para que haja uma melhor compreensão dos assuntos ministrados pelos professores, sempre se fez uso de ferramentas de apoio pedagógicos, como os livros e textos complementares. Mais recentemente, com a maior informatização do ambiente escolar, tem sido cada vez maior a presença de ferramentas de tecnologia na sala de aula. Com o surgimento da pandemia da covid-19, a aparição de tais ferramentas tem sido mais pronunciada. Como muitos locais de ensino passaram a adotar a modalidade de aulas à distância, o aluno surdo foi especialmente atingido porque poucas instituições puderam dar o suporte adequado para que esses alunos pudessem minimizar as perdas inerentes ao distanciamento. Existem várias modalidades de softwares que se destinam a traduzir o português para a Libras, e passou-se a questionar se tais ferramentas seriam capazes de, em certo grau, substituir o intérprete de Libras. 0 desenvolvimento tecnológico é um fenômeno inerente à história da humanidade. Sempre se busca apetrechos que possam facilitar as atividades laborais das pessoas. É evidente que em muitos campos de trabalho, os dispositivos eletrônicos chegam mesmo a substituir a mão de obra humana, como nas compras on-line, em várias etapas nas fábricas automotivas ou nas instituições bancárias.

Após todas estas considerações, o presente trabalho se propõe a identificar através da revisão sistemática da literatura, as ferramentas de tecnologias digitais destinadas à informação e comunicação que são mais utilizados para a tradução do português para a Libras pela comunidade surda no contexto educacional.

\section{Software tradutores português-Libras}

Segundo Marques de Melo (1975), “Comunicação é o processo de transmissão e recuperação de informações”, mas, ao se analisar o processo comunicativo, cada ciência utiliza sua própria perspectiva. Atualmente a linguagem, a cultura e a tecnologia são elementos indissociáveis do processo de comunicação. Com o passar do tempo, com o aumento da complexidade das relações humanas, a necessidade de comunicar-se tornou-se uma necessidade. Segundo Mayr (2006), “uma pessoa do século XXI vê o mundo de uma maneira bem diferente de um cidadão da era vitoriana e que essa mudança teve fontes múltiplas, em particular os incríveis avanços da tecnologia".

A criação formal e o desenvolvimento da comunicação de indivíduos surdos 
tiveram seu alvorecer através de D. Pedro II, com a constituição do Imperial Instituto dos Surdos-Mudos. Em 06 de julho de 2015, instituiu-se no Brasil a Lei Brasileira de Inclusão da Pessoa com Deficiência que traz no seu artigo $1^{0}$ : “destinada a assegurar e a promover, em condições de igualdade, o exercício dos direitos e das liberdades fundamentais por pessoa com deficiência, visando à sua inclusão social e cidadania."

Como consequência das mais variadas conquistas da comunidade surda, houve inegavelmente uma melhora na educação dessas pessoas, como um aumento de 47,6\% na quantidade de alunos surdos na educação básica de 2006 a 2012; na educação superior de 2.428 alunos em 2006 para 5.660 em 2011 (MEC/SECADI 2014, Apud Santos, Coutinho, Brito, 2016). Porém esses mesmos dados revelam que apenas $15,62 \%$ das pessoas surdas estão matriculadas. E são vários os fatores que demonstram esses fracassos escolares dos alunos surdos, como o fracasso nas políticas públicas que não dão suporte necessários aos alunos como é garantido por lei e nem formam professores habilitados para interagir com esses alunos.

No encalço de tamanhas e rápidas transformações e dos crescentes desafios que se têm pela frente, o uso de tecnologias com um intuito de dar um maior suporte aos surdos tem se mostrado muito promissor. A tecnologia assistida (TA) pode ser definida como sendo: "uma área do conhecimento, de característica interdisciplinar, que engloba produtos, recursos, metodologias, estratégias, práticas e serviços que objetivam promover a funcionalidade, relacionada à atividade e participação, de pessoas com deficiência, incapacidades ou mobilidade reduzida, visando sua autonomia, independência, qualidade de vida e inclusão social." (Comitê de Ajudas Técnicas, Corde/SEDH/PR, 2007, Apud Nazari et al, 2017), podendo ser utilizada como um instrumento que visa uma maior inclusão social, proporcionando com isso maior autonomia e qualidade de vida.

Os programas de computador e os aplicativos para telefones móveis (smartphones) destinados à educação de surdos são uma TA que se propõem a potencializar o ensino de alunos surdos. Os programas mais utilizados e populares podem ser assim caracterizados conforme: Sigrist, Siqueira e Cunha, 2021; Ossada e Rodrigues, 2016; Rocha e Melgaço, 2018; Santos e Dantas, 2017; Rocha; Martins; Silva e Farias, 2018. 
- Hand Talk (https://www.handtalk.me/br): este é o programa mais popular entre os ouvintes e surdos. Destina-se à tradução de línguas escritas e orais para as línguas de sinais e também da língua de sinais para as línguas faladas e escritas.

- VLibras (https://www.gov.br/governodigital/pt-br/vlibras): este aplicativo “é o resultado de uma parceria entre o Ministério da Economia (ME), por meio da Secretaria de Governo Digital (SGD), e a Universidade Federal da Paraíba (UFPB), através do Laboratório de Aplicações de Vídeo Digital (LAVID)."

- ProDeaf: segundo sua descrição, “Traduza frases e palavras de português para Língua Brasileira de Sinais (Libras), ou de inglês para Língua Americana de Sinais (ASL). O único com Dicionário e Tradutor de Libras e ASL. Em 2018 a Hand Talk a adquiriu.

- Librol: segundo sua descrição é um software que traduz textos em português para Libras, mas sem o uso de sinais.

- LibrasTI (http://r1.ufrrj.br/petsi/librasti/)): destina-se ao ensino de termos de Tecnologia da Informação para o público surdo.

- Rybená (https://portal.rybena.com.br/site-rybena/): é uma tecnologia assistiva que traduz textos do português para Libras e Voz.

- Karytu: desenvolvido por Angela Carrancho da Silva, esse software tem por finalidade atender crianças surdas em fase de letramento.

\section{Material e métodos}

O presente trabalho foi formulado tomando como base o método de Revisão Sistemática da Literatura (RSL), partindo-se como fonte bibliográfica o trabalho proposto por (Kitchenham e Charters, 2007 apud Santos, et. Al, 2017).). Como proposto por este autor, “pesquisadores que conduzem uma revisão sistemática devem se esforçar ao máximo para identificar e relatar a pesquisa que não necessariamente suporta as suas hipóteses de pesquisa preferidas, bem como identificar e relatar pesquisas que embasam os resultados." As Revisões Sistemáticas são o resultado da análise de estudos individuados (os estudos primários), e por tal fato são consideradas o melhor nível de evidência. Uma revisão sistemática responde a uma pergunta claramente formulada utilizando 
métodos sistemáticos e explícitos para identificar, selecionar e avaliar criticamente pesquisas relevantes, e coletar e analisar dados de estudos incluídos na revisão (Clarke 2001, apud Santos, et. Al, 2017).

Tendo como ponto de partida o questionamento principal ao qual se refere este trabalho, inicialmente foram formuladas três strings de busca ou palavraschave com o intuito de tornar a pesquisa mais abrangente. Sendo assim, as expressões da pesquisa foram alocadas nesses três grupos, conforme demonstrado no quadro 01.

Quadro 1 - Palavras para strigs de busca.

\begin{tabular}{|l|l|l|}
\hline $1^{\text {a }}$ Ordem & $2^{\text {a }}$ Ordem & $3^{\text {a }}$ Ordem \\
\hline Tecnologia Assistiva & $\begin{array}{l}\text { Software de tradução } \\
\text { Software tradutor }\end{array}$ & $\begin{array}{l}\text { Libras, Língua Brasileira de } \\
\text { Sinais }\end{array}$ \\
\hline
\end{tabular}

Fonte: Próprio autor.

Após obedecer à ordem das strings $\left(1^{\mathrm{a}}, 2^{\mathrm{a}}\right.$ e $\left.3^{\mathrm{a}}\right)$, foram elencadas em seguida três strings, em que na primeira string, tomando como parâmetro a base de dados somente do google acadêmico, identificou-se vinte e oito trabalhos na primeira string, na segunda, viu-se onze trabalhos e na terceira, nenhum trabalho, conforme se verifica no quadro 02.

Quadro 02 - Strings formadas para buscas no google acadêmico.

\begin{tabular}{|l|l|}
\hline String & GA \\
\hline $\begin{array}{l}\text { "Tecnologia Assistiva"+"Software de tradução"+"Língua Brasileira de } \\
\text { Sinais" ou "libras" }\end{array}$ & 28 \\
\hline $\begin{array}{l}\text { "Tecnologia Assistiva"+"Software tradutor"+"Língua Brasileira de } \\
\text { Sinais" ou "libras" }\end{array}$ & 11 \\
\hline $\begin{array}{l}\text { "Tecnologia Assistiva"+"Suporte para Surdos"+"Língua Brasileira de } \\
\text { Sinais" ou "libras" }\end{array}$ & 0 \\
\hline
\end{tabular}

Fonte: próprio autor

Após a busca no google acadêmico através das strings foi organizada uma tabela no excel com o intuito de selecionar apenas os trabalhos que iriam compor essa pesquisa, sendo assim foram excluídos teses de doutorado, dissertação de 
mestrado, trabalho de conclusão de cursos de graduação e capítulos de Livros, ficando a pesquisa restrita apenas as análises de artigos completos publicados em periódicos e trabalhos completos publicados em anais de eventos. Dessa forma, o próximo passo foi selecionar os critérios de inclusão e exclusão utilizados para compor o trabalho, mostrados no quadro 03.

Quadro 03 - Critérios de inclusão ou exclusão de materiais das etapas da pesquisa.

\begin{tabular}{|c|c|c|}
\hline Critérios & ID & Descrição \\
\hline \multirow[t]{3}{*}{ Inclusão } & C1 & $\begin{array}{l}\text { Artigos completos ou resumidos publicados em periódicos } \\
\text { científicos das bases listadas. }\end{array}$ \\
\hline & $\mathrm{C2}$ & $\begin{array}{l}\text { Apresentar experiências de aprendizagem com uso dos } \\
\text { softwares de tradução. }\end{array}$ \\
\hline & C3 & $\begin{array}{l}\text { Artigos que abordam sobre os softwares de tecnologia } \\
\text { assistiva com foco na tradução automática português Libras. }\end{array}$ \\
\hline \multirow[t]{4}{*}{ Exclusão } & E1 & Artigos duplicados ou semelhantes. \\
\hline & E2 & $\begin{array}{l}\text { Artigos apenas com carácter publicitário ou de marketing } \\
\text { publicados em magazines. }\end{array}$ \\
\hline & E3 & Apresentação de slides. \\
\hline & E4 & $\begin{array}{l}\text { Artigos que aparentemente não contribuem para a pesquisa } \\
\text { vigente. }\end{array}$ \\
\hline
\end{tabular}

Fonte: próprio autor

Com a verificação e análise através da leitura do título, palavras-chave e resumo foram selecionados para leitura completa um total de onze trabalhos dos quais quatro foram excluídos por não responder as perguntas norteadora desse trabalho. Pois esta pesquisa busca-se responder a questionamentos bem como as motivações que levaram a tais perguntas, conforme explicitado no quadro 04.

Quadro 04 - Perguntas da pesquisa e suas motivações.

\section{ID}

Motivação 


\begin{tabular}{|l|lr|ll|} 
P1 & $\begin{array}{l}\text { Quais as vantagens ou } \\
\text { desvantagens são observadas } \\
\text { pelos usuários das ferramentas de } \\
\text { tradução português Libras nos } \\
\text { diversos contextos? }\end{array}$ & $\begin{array}{l}\text { Enten o contexto em que essas } \\
\text { ferramentas são mais utilizadas para } \\
\text { acessibilidade linguística da pessoa } \\
\text { surda. }\end{array}$ \\
\hline P2 & $\begin{array}{l}\text { Como se organiza } \\
\text { linguisticamente a Libras? }\end{array}$ & $\begin{array}{l}\text { Conhecer a estrutura linguística da } \\
\text { Língua Brasileira de Sinais. }\end{array}$ \\
\hline P3 & $\begin{array}{l}\text { Como os usuários avaliam o uso } \\
\text { de TDICs no contexto acadêmico? }\end{array}$ & $\begin{array}{l}\text { Analisar a avabilidade da ferramenta. } \\
\text { usana sobre a }\end{array}$ \\
\hline
\end{tabular}

Fonte: próprio autor

\section{Resultados e discussão}

Com o objetivo de responder às perguntas da pesquisa inicialmente foram selecionados onze trabalhos, sendo sete artigos completos publicados em periódicos e cinco trabalhos completos publicados em anais de eventos, diante disso foi realizada a leitura dos resumos para análise conforme os critérios de inclusão e exclusão, após a exclusão de quatro artigos conforme os critérios definidos na pesquisa, foi feita a leitura completa dos sete selecionados com o intuito de responder pelo menos a uma das três questões definidas na pesquisa.

Para responder à pergunta um "Quais as vantagens ou desvantagens são observadas pelos usuários das ferramentas de tradução português Libras nos diversos contextos?" foi observado o que os autores apresentam a seguir.

Ossada e Rodrigues ( 2016) apresentam uma revisão com o objetivo de identificar a capacidade dos sistemas em substituir o intérprete de Libras apoiados na tecnologia da informação, no período de 2004 a 2015 e concluiu que dos dezoito softwares analisados apenas três tiveram seus estudos finalizados, porém segundo os autores os mesmo ainda não são capazes de substituir os intérpretes de Libras humano, pois uma desvantagem do uso destas ferramentas é identificado quando se trata de uso cotidiano, onde estas não conseguem transmitir com naturalidade e não consegue atender a todos os parâmetros gramaticais da Libras sendo um deles 
a expressão facial e corporal, apresentando esta desvantagem os autores orienta apenas o uso dessas ferramentas para uma comunicação de pequenas traduções em que não seja necessário usar as expressões faciais e corporais. Sendo a Libras uma língua de modalidade visual e gestual em que o parâmetro expressão facial e corporal faz parte da gramática da língua o que os autores consideram como uma pequena tradução?

Rocha; Martins; Silva e Farias (2018) pesquisam sobre as tecnologias assistivas que podem contribuir para o ensino aprendizagem da língua portuguesa como segunda língua para surdos, para tanto apresentam como vantagem o aumento nos últimos dez anos dessas pesquisas e assim apresentam alguns softwares de tradução e em sua grande maioria são aplicativos mobile o que para os autores é algo mais viável e os considera importantes na educação de surdos, no entanto não realizaram nenhum teste para saber se atende a necessidade dos usuários desses softwares, as desvantagens apresentadas pelos autores sobre tais ferramentas já existente é devido estas não apresentarem o ensino da língua portuguesa como principal objetivo não conseguindo assim auxiliar na interpretação de palavras textos.

O mapeamento realizado por Oliveira, Gomes e Freire (2018) teve como objetivo demonstrar de forma sistemática as abordagens das tecnologias assistivas para o auxílio na inclusão de pessoas surdas na educação, sendo assim o trabalho foi dividido em 11 categorias considerando a tecnologia utilizada como forma de incluir a pessoa surda, sendo que a categoria dois apenas indica os softwares tradutores de português para Libras que auxiliam na comunicação entre ouvintes e surdos.

O estudo realizado por Sigrist, Siqueira e Cunha (2021) se propõem a identificar como a inteligência artificial junto com o reconhecimento óptico de caracteres $(O C R)$ podem contribuir na tradução de documentos e livros escritos para Libras, assim como Ossada e Rodrigues (2016), Rocha; Martins; Silva e Farias (2018) e Oliveira, Gomes e Freire (2018), os autores apresentam inicialmente as ferramentas selecionando as mesma utilizadas pelos autores citados anteriormente que realizam esse serviço de tradução do português para Libras e conclui que essas ferramentas são de grande utilidade para inserir pessoas surdas no mercado de trabalho e em outros ambientes, não citados pelos autores. No entanto os 
pesquisadores veem como desvantagem o programa não permitir que o usuário escaneie uma imagem, e que a partir dessa imagem possa ser feito a tradução do que tem escrito nela, opções que os autores relatam existir em outros aplicativos de tradução de línguas naturais, uma outra desvantagem considerada pelos autores sobre estas ferramentas é a falta de estudos sobre a semântica da Libras para que a ferramenta seja capaz de fazer uma boa tradução aproximando ao máximo das línguas naturais.

Santos e Dantas (2017) bem como Ossada e Rodrigues (2016), Rocha; Martins; Silva e Farias. (2018), Oliveira, Gomes e Freire (2018) e Sigrist, Siqueira e Cunha (2021) apresentam as tecnologias que podem ser utilizadas pelas pessoas com deficiência auditiva, porém, Santos e Dantas (2017) não chegaram a realizar nenhum teste para saber a viabilidade.

Já a segunda pergunta de "Como se organiza linguisticamente a Libras?" onde buscou conhecer a estrutura linguística da Língua Brasileira de Sinais.

Dentre os autores selecionados não foi possível identificar nenhum trabalho que pudesse responder a segunda pergunta, pois percebe-se que em sua totalidade, esses trabalhos estão voltados para área de tecnologia nesse sentido abre caminho para que pesquisas possam ser aprofundadas buscando um viés na linguística.

A fim de buscar respostas para a pergunta três "Como os usuários avaliam o uso de TDICs no contexto acadêmico?" foram analisados os trabalhos de Rocha; Martins; Silva e Farias (2018) o qual não chegaram a responder a pergunta devido a pesquisa não ter sido concluída pelos autores, sendo apresentado somente até a etapa de elaboração de uma tecnologia assistiva que possa colaborar com a aprendizagem de português como segunda língua pelos surdos, como a etapa de avaliação proposta pelos autores não foi alcançada, a pergunta não obteve sua resposta.

Contudo encontramos em Da Luz (2021) uma pesquisa que apresenta o uso de softwares educacionais em libras no campo educacional, no qual o autor apresenta algumas ferramentas e aponta algumas dessas que podem contribuir muito para o ensino de pessoas surdas, para isso ele realizou uma pesquisa de campo na capital do estado do Mato Grosso, no ano de 2018 tendo como 
colaboradores os tradutores intérpretes de Libras das instituições pesquisadas que apontaram fazer uso de softwares tradutores de português Libras, mas que estes não desempenham satisfatoriamente as funções de divulgação, propagação e registro da Libras. Por isso o autor conclui que, os softwares podem contribuir muito para o ensino aprendizagem de pessoas surdas, desde que a Libras passe a ser mais conhecida e falada pela população em geral.

Santos e Dantas (2017) assim como Rocha; Martins; Silva e Farias (2018) apresenta em sua pesquisa algumas tecnologia assistiva que podem ser utilizadas pelas pessoas com deficiência auditiva na mediação técnico pedagógica no ensino superior, dentre essas TA's os autores apresentam os softwares de tradução como uma possibilidade de facilitar a interação entre a pessoa surda usuária da Libras com os professores e colegas que desconhece a Língua Brasileira de Sinais tornando assim um ambiente mais inclusivo, buscando mostrar a importância das tecnologias assistiva no ambiente educacional os pesquisadores entrevistaram um surdo que não tem nas aulas o acompanhamento de um intérprete de libras educacional, mas que devido ter fluência na língua portuguesa faz uso de um software que converte áudio do que é explicado em sala de aula pelo professores em texto escrito no seu computador, sendo assim os autores apontam a necessidade das tecnologias assistiva e sua divulgação no ambiente acadêmico.

Logo, diante dessa análise percebe-se que existem muitas tecnologias assistivas que podem contribuir para o ensino aprendizagem da pessoa surda no ambiente escolar, mas que ainda são pouco divulgadas e conhecidas pela comunidade acadêmica.

Por tanto sugere-se o aprofundamento do estudo das ferramentas que realizam a tradução de português Libras de forma a mostrar as possibilidades de uso dentro do espaço escolar.

\section{Conclusões}

Esse estudo possibilitou identificar que alguns softwares de tradução português Libras já são conhecidos pelo a comunidade surda e que já existem 
pesquisas focadas no ensino da Libras ou da Língua portuguesa por meio do uso dessas ferramentas. No entanto, quando se trata da função de atender como ferramenta que possa contribuir na tradução de português Libras dentro do contexto acadêmico essas pesquisas não apresentam um estudo aprofundado sobre a organização linguística da Libras.

$\mathrm{Na}$ construção desta RSL foi identificado algumas pesquisas ainda em andamento com o objetivo de ensinar português como segunda língua e outra trazendo uma inovação propondo a criação de uma ferramenta que possa fazer a tradução de textos escritos para língua de sinais a partir de uma imagem. Sendo assim, pode-se concluir com os resultados desta pesquisa que as ferramentas são utilizadas e conhecidas pela comunidade surda para comunicação e tradução de frases mais simples, mas nenhuma destas foram aplicadas para tradução de aulas, são usadas no contexto escolar, mas não neste viés de traduzir aulas.

\section{Referências}

ALVES, Tatiane Lemos. Biblioteca acessível: eliminando barreiras. Revista Brasileira de Biblioteconomia e Documentação, São Paulo, v. 13, p. 1883-1898, dez. 2017. ISSN 1980-6949. Disponível em: <https://rbbd.febab.org.br/rbbd/article/view/915>. Acesso em: 24 set. 2021.

AMARANTE, E.; AZEVEDO, A.; MIGUEL, J. Exibição cinematográfica acessível: alternativas e limitações nas políticas públicas e na oferta de conteúdos. Comunicação \& amp; Informação, Goiânia, Goiás, v. 23, 2020. DOI: 10.5216/ci.v23.66241. Disponível em: https://www.revistas.ufg.br/ci/article/view/66241. Acesso em: 24 set. 2021.

BRASIL, 2015, Lei n. 13.146, de 6 de jul. de 2015. Lei Brasileira de Inclusão da Pessoa com Deficiência. Disponível em: http://www.planalto.gov.br/ccivil_03/_ato20152018/2015/lei/l13146.htm ; acesso em: 24 Set. 2021.

BRASIL. Conselho Nacional de Educação. Resolução n. 2, de 11 de setembro de 2001, institui as Diretrizes Nacionais para a Educação Especial na Educação Básica. Brasília: CNE/CEB, 2001. Disponível em: http://portal.mec.gov.br/cne/arquivos/pdf/CEB0201.pdf Acesso em: 27/09/2021.

CAETANO, Michele S. da M.; PASSOS, Marize L. S.; SONDERMANN, Danielli V. C.; NOBRE, Isaura M. N. O uso de Recursos Digitais no Processo de Inclusão de Alunos com Deficiência: Reflexões sobre os Trabalhos Produzidos pelos Alunos de uma Pós-graduação em Informática na Educação do Instituto Federal do Espírito Santo. Conference: XV Congresso Brasileiro de Ensino Superior a Distância (ESUD) e o IV Congresso Internacional de Educação Superior a Distância (CIESUD), Natal, 2018.

DA LUZ, Antuerbey A. A. F. Utilização de Softwares para Registro da Língua Brasileira de Sinais por Usuários do Campo Educacional na Cidade de Cuiabá - MT no ano de 2018. Brazilian Journals 
DE OLIVEIRA. Gabriel C.; GOMES, Maria Eurizene de S.; FREIRE, Emmanuel S. S. O Uso da Tecnologia na Inclusão de Pessoas Surdas no Processo de Ensino e Aprendizagem: Um Mapeamento Sistemático Focado nas Iniciativas Brasileiras. Sánchez, J. (2018) Editor. Nuevas Ideas en Informática Educativa, Volumen 14, p. 70 - 79. Santiago de Chile. Acesso em http://www.tise.cl/Volumen14/TISE2018/70.pdf

MARQUES DE MELO, José. Comunicação Social: teoria e pesquisa. 4. ed. Petrópolis: Vozes, 1975. $300 \mathrm{p}$.

MAYR, Ernst. O impacto de Darwin no pensamento moderno. Scientific American. São Paulo: Duetto, 2006. Edição Especial no. 17. p. 93-98.

MEDEIROS, Magnólia Maria; QUEIROZ, Maria Jane. TICS NA EDUCAÇÃO: O USO DE SOFTWARE LIVRE NA PROMOÇÃO DA ACESSIBILIDADE. Revista Brasileira da Educação Profissional e Tecnológica, [S.l.], v. 1, n. 14, p. e6875, jun. 2018. ISSN 2447-1801. Disponível em: <https://www2.ifrn.edu.br/ojs/index.php/RBEPT/article/view/6875>. Acesso em: 24 set. 2021. doi: https://doi.org/10.15628/rbept.2018.6875.

MIGLIOLI, Sarah.; SANTOS, Gilmara A. dos. Acessibilidade e serviços inclusivos para minorias sociais: A biblioteca do instituto nacional de educação de surdos. Revista ACB: Biblioteconomia em Santa Catarina, ISSN 1414-0594, Vol. 22, №. 1, 2017, págs. 136-149.

OSSADA, Sandra Aparecida R.; RODRIGUES, Silvia Cristina M. A Tecnologia da informação em Colaboração na comunicação dos Deficientes Auditivos. FaSCi-Tech (ISSN 2176-9427) v. 1, n. 10 $\underline{(2016)}$

ROCHA, Scheilla; MARTINS, José; SILVA, José; FARIAS, Mário. L2: Aplicativo para Aprendizagem de Língua Portuguesa para Alunos Surdos. In: ESCOLA REGIONAL DE COMPUTAÇÃO BAHIA, ALAGOAS E SERGIPE (ERBASE), 18. , 2018, Aracaju. Anais [...]. Porto Alegre: Sociedade Brasileira de Computação, 2018 . p. 474-483.

SANTOS, Emmerson et al. Mapeamento sistemático acerca das práticas docentes com o uso de Recursos Educacionais Abertos. Brazilian Symposium on Computers in Education (Simpósio Brasileiro de Informática na Educação - SBIE), [S.l.], p. 263, out. 2017. ISSN 2316-6533. Disponível em: <https://www.br-ie.org/pub/index.php/sbie/article/view/7555>. Acesso em: 27 set. 2021. doi:http://dx.doi.org/10.5753/cbie.sbie.2017.263.

SANTOS, P. K. dos; DANTAS, N. M. R. Tecnologias assistivas e a inclusão do estudante surdo na educação superior. Revista Internacional de Educação Superior, Campinas, SP, v. 3, n. 3, p. 494514, 2017. DOI: 10.22348/riesup.v3i3.7793. Disponível em: https://periodicos.sbu.unicamp.br/ojs/index.php/riesup/article/view/8650620. Acesso em: 24 set. 2021.

SANTOS, Sylvana Karla S. L.; MENDES, Núbia Flávia O.; SILVA, Queila Pahim da. Propostas para o Atendimento às Pessoas Surdas em Serviços de Governo Eletrônico. In: WORKSHOP DE COMPUTAÇÃO APLICADA EM GOVERNO ELETRÔNICO (WCGE), 9. , 2021, Evento Online. Anais [...]. 
ARAÚJO, A. C. S. e OLIVEIRA, F. K..(2021)

Revisão Sistemática da Literatura sobre Tecnologias digitais de informação e comunicação de tradução do par linguístico

Porto Alegre: Sociedade Brasileira de Computação, 2021. p. 1-12. ISSN 2763-8723. DOI: https://doi.org/10.5753/wcge.2021.15971.

SIGRIST, V. C.; SIQUEIRA, A. H. DE L.; CUNHA, D. P. Estudo para implementação de software de tradução automática para libras. Revista Processando o Saber, v. 13, p. 154-169, 9 jun. 2021. 